\title{
青藏高原高寒区阔叶林植被固碳现状、速率和潜力
}

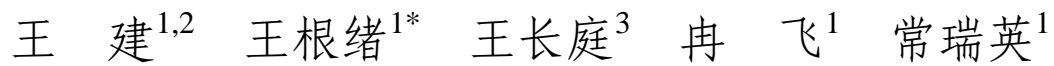 \\ ${ }^{1}$ 中国科学院成都山地灾害与环境研究所中国科学院山地表生过程与生态调控重点实验室, 成都 $610041 ;{ }^{2}$ 中国科学院大学, 北京 $100049 ;{ }^{3}$ 西南民族 \\ 大学生命科学与技术学院, 成都 610041
}

摘 要 为明晰青藏高原高寒区阔叶林植被碳储量现状及其动态变化特征, 利用森林资源清查数据和标准样地实测数据, 估 算了青藏高原高寒区(青海和西藏两省区)阔叶林植被的碳储量、固碳速率和固碳潜力。结果表明: 2011年青藏高原高寒区阔 叶林植被碳储量为 $310.70 \mathrm{Tg}$, 碳密度为 $89.04 \mathrm{Mg} \cdot \mathrm{hm}^{-2}$ 。六类阔叶林型(栋(Quercus)林、桦木(Betula)林、杨树(Populus)林、其 他硬阔林、其他软阔林和阔叶混交林)中, 阔叶混交林的碳储量最大, 杨树林碳储量最小; 其他硬阔林碳密度最大, 其他软阔 林碳密度最小。空间分配上碳储量和碳密度表现为: 乔木层>灌木层>凋落物层>草本层>枯死木层。不同龄级碳储量和碳密度 总体表现为随林龄增加逐渐增大的趋势。阔叶林碳储量从2001年的304.26 Tg增加到2011年的310.70 Tg, 平均年固碳量为 0.64 $\mathrm{Tg} \cdot \mathrm{a}^{-1}$, 固碳速率为 $0.19 \mathrm{Mg} \cdot \mathrm{hm}^{-2} \cdot \mathrm{a}^{-1}$ 。不同林型固碳速率表现为其他软阔林最大, 其他硬阔林最小; 不同龄级表现为成熟林最 大, 幼龄林最小。阔叶林乔木层固碳潜力为 $19.09 \mathrm{Mg} \cdot \mathrm{hm}^{-2}$, 且不同林型固碳潜力表现为柇林最大, 桦树林最小。三次调查期 间阔叶林碳储量逐渐增加, 主要原因是近年来森林保护工程的开展使阔叶林生长健康良好。

关键词 碳储量; 固碳速率; 固碳潜力; 阔叶林; 青藏高原高寒区

引用格式: 王建, 王根绪, 王长庭, 由飞, 常瑞英 (2016). 青藏高原高寒区阔叶林植被固碳现状、速率和潜力. 植物生态学报, 40, 374-384. doi: 10.17521/cjpe.2015.0152

\section{Carbon storage and potentials of the broad-leaved forest in alpine region of the Qinghai- Xizang Plateau, China}

WANG Jian ${ }^{1,2}$, WANG Gen-Xü ${ }^{1 *}$, WANG Chang-Ting ${ }^{3}$, RAN Fei ${ }^{1}$, and CHANG Rui-Ying ${ }^{1}$

${ }^{1}$ Key Laboratory of Mountain Surface Processes and Ecological Regulation of Chinese Academy of Sciences, Institute of Mountain Hazards and Environment, Chinese Academy of Sciences, Chengdu 610041, China; ${ }^{2}$ University of Chinese Academy of Sciences, Beijing 100049, China; and ${ }^{3}$ College of Life Science and Technology, Southwest University for Nationalities, Chengdu 610041, China

\section{Abstract}

Aims Our objective was to explore the vegetation carbon storages and their variations in the broad-leaved forests in the alpine region of the Qinghai-Xizang Plateau that includes Qinghai Province and Xizang Autonomous Region.

Methods Based on forest resource inventory data and field sampling, this paper studied the carbon storage, its sequestration rate, and the potentials in the broad-leaved forests in the alpine region of the Qinghai-Xizang Plateau.

Important findings The vegetation carbon storage in the broad-leaved forest accounted for $310.70 \mathrm{Tg}$ in 2011, with the highest value in the broad-leaved mixed forest and the lowest in Populus forest among the six broad-leaved forests that include Quercus, Betula, Populus, other hard broad-leaved species, other soft broad-leaved species, and the broadleaved mixed forest. The carbon density of the broad-leaved forest was 89.04 $\mathrm{Mg} \cdot \mathrm{hm}^{-2}$, with the highest value in other hard broad-leaved species forest and the lowest in other soft broad-leaved species forest. The carbon storage and carbon density in different layers of the forests followed a sequence of overstory layer $>$ understory layer $>$ litter layer $>$ grass layer $>$ dead wood layer, which all increased with forest age. In addition, the carbon storage of broad-leaved forest increased from 304.26 Tg in 2001 to 310.70 $\mathrm{Tg}$ in 2011. The mean annual carbon sequestration and its rate were $0.64 \mathrm{Tg} \cdot \mathrm{a}^{-1}$ and $0.19 \mathrm{Mg} \cdot \mathrm{hm}^{-2} \cdot \mathrm{a}^{-1}$, respectively. The maximum and minimum of the carbon sequestration rate were respectively found in other soft broad-leaved species forest and other hard broad-leaved species forest, with the highest value in the mature forest and the lowest in the young forest. Moreover, the carbon sequestration potential in the tree layer of broad-leaved

收稿日期Received: 2015-04-28 接受日期Accepted: 2015-11-10

* 通信作者Author for correspondence (E-mail: wanggx@imde.ac.cn) 
forest reached $19.09 \mathrm{Mg} \cdot \mathrm{hm}^{-2}$ in 2011, with the highest value found in Quercus forest and the lowest in Betula forest. The carbon storage increased gradually during three inventory periods, indicating that the broad-leaved forest was well protected to maintain a healthy growth by the forest protection project of Qinghai Province and Xizang Autonomous Region.

Key words carbon storage; carbon sequestration rate; carbon sequestration potential; broad-leaved forest; alpine area of Qinghai-Xizang Plateau

Citation: Wang J, Wang GX, Wang CT, Ran F, Chang RY (2016). Carbon storage and potentials of the broad-leaved forest in alpine region of the Qinghai-Xizang Plateau, China. Chinese Journal of Plant Ecology, 40, 374-384. doi: 10.17521/cjpe.2015.0152

森林是陆地碳库的主体, 储存了陆地地上部分 碳库的80\%，地下部分的40\% (Malhi et al., 1999), 在减缓全球气候变化和全球碳循环中有着不可替 代的作用。因此, 明确森林的固碳现状、速率和潜 力, 对合理经营和管理森林, 促进森林的固碳功能 具有重要意义。目前, 针对森林的植被碳储量和碳 汇功能进行了大量的研究(Rice et al., 2004; Akselsson et al., 2005; 杨洪晓等, 2005; 王秀云和孙玉军, 2008; 张玮辛等, 2012; Matsuzaki et al., 2013), 多数 研究集中在全球或国家尺度上(Dixon et al., 1994; 王效科等, 2001; Li et al., 2004; 赵敏和周广胜, 2004)。我国幅员辽阔, 植被类型多样, 各地区碳储 量估算结果存在较大的差异。要准确估算我国森林 碳汇状况, 必须准确估算区域尺度的碳汇现状。有 关森林固碳潜力的研究, 目前主要以模型模拟运算 为主(Ni, 2002; Seely et al., 2002; Zhang \& Xu, 2003; Ge et al., 2013), 且多考虑未来气候变化条件下森 林的固碳潜力(Sperow et al., 2003), 而依据森林自 身林龄发展将当前森林碳储量与历史最大固碳量 之差值作为固碳潜力则很少被关注(Sleutel et al., 2003)。

青藏高原高寒区林区是我国林区的重要组成 部分。目前, 由于缺乏调查资料, 青藏高原高寒区 森林植被碳汇状况缺乏全面系统的研究, 其阔叶林 植被碳汇状况研究更加缺乏。第八次森林清查数据 表明青藏高原高寒区阔叶林面积和蓄积量分别占 整个乔木林的39.32\%和 $21.02 \%$, 足见阔叶林植被在 青藏高原高寒区森林中的重要性。本文以青藏高原 高寒区阔叶林植被为研究对象, 估算其植被层的固 碳现状、固碳速率和固碳潜力, 旨在了解青藏高原 高寒区阔叶林的碳汇现状及其动态变化特征, 为我 国区域尺度的森林碳汇估算研究提供基础数据和 科学参考。

\section{1 研究区域和研究方法}

\section{1 研究区概况}

青藏高原面积 $2.57 \times 10^{6} \mathrm{~km}^{2}$, 约占中国陆地面 积的 $1 / 4$ 。地势上总体呈现由西北向东南倾斜的特 征。气候总体上具有西北部严寒干燥、东南部温暖 湿润的特点。近 20 年来, 青藏高原年平均气温 -1.29 ${ }^{\circ} \mathrm{C}$, 年降水量396 mm (黄玫等, 2008)。青藏高原高 寒区是我国的重要林业基地, 森林面积为 $1.87 \times 10^{7}$ $\mathrm{hm}^{2}$ (其中乔木林面积达 $8.65 \times 10^{6} \mathrm{hm}^{2}$ ), 森林覆盖 率达 $9.63 \%$ (图1), 森林蓄积量为 $2.26 \times 10^{9} \mathrm{~m}^{3}$ (其中 乔木林蓄积量达 $4.07 \times 10^{8} \mathrm{~m}^{3}$ ), 其中, 阔叶林面积 为 $3.4 \times 10^{6} \mathrm{hm}^{2}$, 占乔木林的 $39.32 \%$, 蓄积量为 8.56 $\times 10^{7} \mathrm{~m}^{3}$, 占乔木林的 $21.02 \%$ 。从树种组成看, 阔叶 林中不同树种(组)面积比例由大到小依次为: 阔叶 混交林(59.57\%)、栋(Quercus, 14.76\%)类、其他硬阔 (6.18\%)、桦木(Betula, $4.19 \%)$ 、其他软阔类(3.61\%) 和杨树(Populus, 2.32\%) (数据来自青海和西藏两省 区森林清查资料)。

本文获得的森林资源清查数据包括: 青海省 1998年、2003年和2008年森林资源清查资料, 西藏 自治区2006年和2011年森林资源清查结果, 其中 2001年西藏自治区森林面积和蓄积资料是根据 2001-2006年乔木林生长量和消耗量推算得出。由 于两省区森林资源清查时间上略有差异, 以西藏自 治区3次森林清查时间为准(即2001年、2006年和 2011年)进行估算。

\section{2 样地设置及取样}

2010年, 在青海和西藏两省区按照典型选样的 方法, 分别在栎林、桦木林、杨树林、其他硬阔林、 其他软阔林和阔叶混交林 6 个林分类型中设置 $50 \mathrm{~m}$ $\times 20 \mathrm{~m}$ (部分样地因地形和分布面积限制, 大小设 置为 $30 \mathrm{~m} \times 20 \mathrm{~m}$ ) 的标准样地 37 个, 其中, 栋类林 


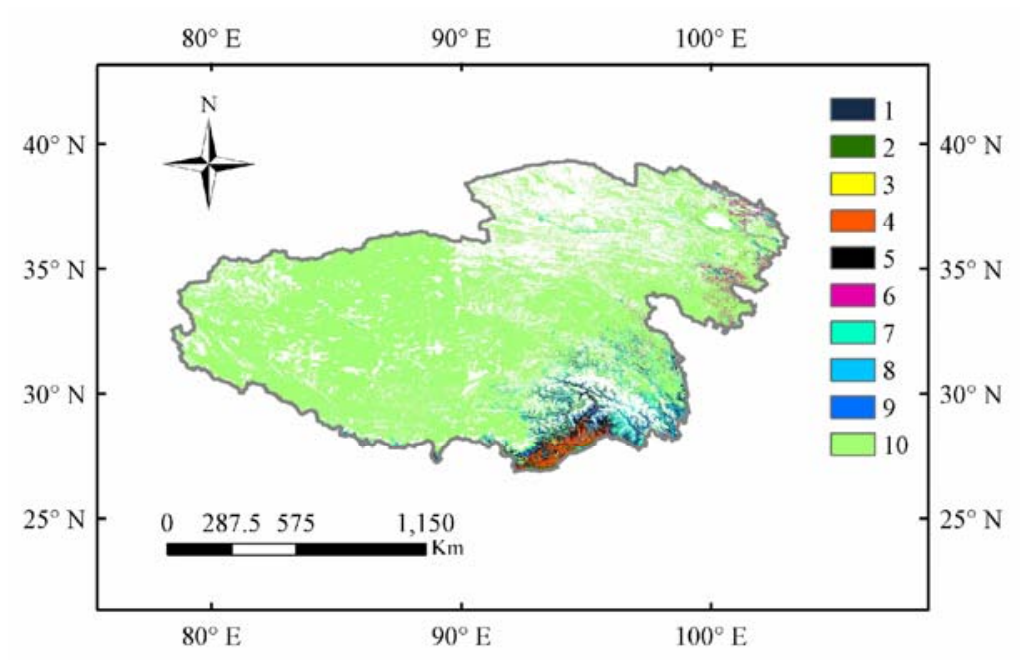

图1 青藏高原高寒区植被分布图。1, 常绿针叶林; 2, 常绿阔叶林; 3, 落叶针叶林; 4, 落叶阔叶林; 5, 混交林; 6, 郁闭灌丛; 7, 开放灌丛; 8, 稀树草原; 9, 热带稀树草原; 10, 草地。土地利用数据(1:100万)来自中国西部环境与生态科学数据中心 (http://westdc.westgis.ac.cn)。

Fig. 1 Vegetation map in alpine area of Qinghai-Xizang Plateau. 1, evergreen needleleaf forest; 2, evergreen broadleaf forest; 3, deciduous needleleaf forest; 4, deciduous broadleaf forest; 5 , mixed forest; 6 , closed shrublands; 7 , open shrublands; 8 , woody savannas; 9, savannas; 10, grasslands. The landuse data (1:1 000 000) was from the Environmental and Ecological Science Data Center for the West China (http://westdc.westgis. ac.cn).

6 个, 桦木林 15 个, 杨树林 9 个, 其他软阔林 5 个, 其 他硬阔林 1 个, 阔叶混交林 1 个。对样地内所有胸径 大于 $5 \mathrm{~cm}$ 的乔木进行每木检尺, 测定胸径和树高。 在每个乔木样方中设置 3 个 $5 \mathrm{~m} \times 5 \mathrm{~m}$ 的灌木样方, 在每个灌木样方中设置 1 个 $1 \mathrm{~m} \times 1 \mathrm{~m}$ 的草本样方, 共设置灌木样方和草本样方各 111 个。在各乔木样方 中设置 3 个 $1 \mathrm{~m} \times 1 \mathrm{~m}$ 的调落物样方, 共计 111 个。最 后分别采集乔木层、灌木层、草本层、枯落物层和 枯死木层各部分器官约200 g样品带回实验室, 用于 分析含水率和有机碳含量。有机碳含量采用重铬酸 钾-硫酸氧化法进行测定(黄从德等, 2008)。阔叶林不 同龄级的划分标准详见表2 (中华人民共和国国家 质量监督检验检疫总局, 中国国家标准化管理委员 会, 2011)。

\section{3 研究方法}

\subsection{1 固碳现状计算}

\subsubsection{1 碳密度的计算}

乔木层碳储量测定 根据森林固碳课题办公 室 ${ }^{\circledR}$ 提供的各主要树种的异速生长方程(表1), 求算 各样方内所有乔木的生物量, 乘以相应器官含碳量 累加得到样方内乔木层碳储量 $\left(\mathrm{Mg} \cdot \mathrm{hm}^{-2}\right)$ (林虹等, 2014; 王宁, 2014)。

(1) 森林固碳课题办公室 (2014). 生物量估算方程. 中国科学院战略先 导性专项-应对气候变化的碳收支认证及其相关问题专项-中国森林生态 系统固碳现状、速率、机制和潜力课题, 37-51.

www.plant-ecology.com
林下植被碳储量测定 采用全收获法收集各 灌木、草本小样方内所有样品称其总鲜质量, 并取 部分样品带回实验室烘干测算含水率，根据含水率 将各小样方灌木、草本鲜质量换算至其干质量并乘 以对应器官含碳量求得样方林下灌草碳储量 $\left(\mathrm{Mg} \cdot \mathrm{hm}^{-2}\right)$ 。

调落物和枯死木碳储量测定 将样方内全部 枯落物烘干推算其生物量, 根据枯落物的碳含量计 算调落物的碳储量 $\left(\mathrm{Mg} \cdot \mathrm{hm}^{-2}\right)$ 。枯死木则按形态(枯 立木、枯倒木)和腐烂等级(轻度、中度和重度)进行 分类, 分别计算枯立木和枯倒木的体积, 并根据不 同腐烂等级的密度计算枯死木的干质量, 结合相应 腐烂等级样本的碳含量得到枯死木的碳储量 $\left(\mathrm{Mg} \cdot \mathrm{hm}^{-2}\right)$ 。

植被碳储量测定 将上述各层碳密度累加得 到某阔叶林植被碳密度 $\left(\mathrm{Mg} \cdot \mathrm{hm}^{-2}\right)$ 。

\subsubsection{2 固碳现状的估算}

结合森林清查资料和以往研究(罗天祥, 1996; 蔡丽莎, 2009; 葛立雯等, 2013)得到的6类阔叶林不 同龄级的碳密度和面积, 估算研究区2011年阔叶林 植被碳储量 $\left(C_{\mathrm{F}}, \mathrm{Tg}\right)$ 。

$$
C_{\mathrm{F}}=\sum_{i=1}^{i} \sum_{j=1}^{j}\left(C_{\mathrm{F}, i} \times A_{\mathrm{F}, i}\right) / 1000000
$$

式中, $C_{\mathrm{F}, i}$ 为第 $i$ 种阔叶林类型第 $j$ 个林龄的森林生态 
表1 青藏高原高寒区阔叶林各优势树种生物量异速生长方程

Table 1 The allometric biomass equations of dominant species in the broad-leaved forests in the alpine region of the Qinghai-Xizang Plateau

\begin{tabular}{|c|c|c|c|}
\hline $\begin{array}{l}\text { 树种 } \\
\text { Forest species }\end{array}$ & $\begin{array}{l}\text { 西藏自治区生物量方程 } \\
\text { Allometric equations in Xizang Autonomous Region }\end{array}$ & $\begin{array}{l}\text { 树种 } \\
\text { Forest species }\end{array}$ & $\begin{array}{l}\text { 青海省生物量方程 } \\
\text { Allometric equations in Qinghai Province }\end{array}$ \\
\hline \multirow{4}{*}{$\begin{array}{l}\text { 栎类 } \\
\text { Quercus spp. }\end{array}$} & $W_{\mathrm{L}}=0.3402\left(D^{2} H\right)^{0.4670}$ & \multirow{4}{*}{$\begin{array}{l}\text { 山杨 } \\
\text { Populus davidiana }\end{array}$} & $W_{\mathrm{L}}=0.0033\left(D^{2} H\right)^{0.8820}$ \\
\hline & $W_{\mathrm{B}}=0.03427\left(D^{2} H\right)^{0.8887}$ & & $W_{\mathrm{B}}=0.0093\left(D^{2} H\right)^{0.8950}$ \\
\hline & $W_{\mathrm{S}}=0.1202\left(D^{2} H\right)^{0.9773}$ & & $W_{\mathrm{S}}=0.0413\left(D^{2} H\right)^{0.8663}$ \\
\hline & $W_{\mathrm{R}}=0.8062\left(D^{2} H\right)^{0.7025}$ & & $W_{\mathrm{R}}=0.0183\left(D^{2} H\right)^{0.8527}$ \\
\hline \multirow{4}{*}{$\begin{array}{l}\text { 杨树 } \\
\text { Populus spp. }\end{array}$} & $W_{\mathrm{L}}=0.0078\left(D^{2} H\right)^{0.7753}$ & \multirow{4}{*}{$\begin{array}{l}\text { 其他杨树 } \\
\text { Other Populus spp. }\end{array}$} & $W_{\mathrm{L}}=0.0035\left(D^{2} H\right)^{0.8774}$ \\
\hline & $W_{\mathrm{B}}=0.026\left(D^{2} H\right)^{0.7655}$ & & $W_{\mathrm{B}}=0.0095\left(D^{2} H\right)^{0.8951}$ \\
\hline & $W_{\mathrm{S}}=0.0529\left(D^{2} H\right)^{0.8364}$ & & $W_{\mathrm{S}}=0.0417\left(D^{2} H\right)^{0.8860}$ \\
\hline & $W_{\mathrm{R}}=0.0079\left(D^{2} H\right)^{0.9577}$ & & $W_{\mathrm{R}}=0.0289\left(D^{2} H\right)^{0.7860}$ \\
\hline \multirow{4}{*}{$\begin{array}{l}\text { 其他树种 } \\
\text { Other species }\end{array}$} & $W_{\mathrm{L}}=0.0075\left(D^{2} H\right)^{0.8592}$ & \multirow{4}{*}{$\begin{array}{l}\text { 其他树种 } \\
\text { Other species }\end{array}$} & $W_{\mathrm{L}}=0.0075\left(D^{2} H\right)^{0.8592}$ \\
\hline & $W_{\mathrm{B}}=0.0079\left(D^{2} H\right)^{1.007}$ & & $W_{\mathrm{B}}=0.0079\left(D^{2} H\right)^{1.007}$ \\
\hline & $W_{\mathrm{S}}=0.0401\left(D^{2} H\right)^{0.8514}$ & & $W_{\mathrm{S}}=0.0401\left(D^{2} H\right)^{0.8514}$ \\
\hline & $W_{\mathrm{R}}=0.0176\left(D^{2} H\right)^{0.8841}$ & & $W_{\mathrm{R}}=0.0176\left(D^{2} H\right)^{0.8841}$ \\
\hline
\end{tabular}

$D$, 乔木胸径 $(\mathrm{cm}) ; H$, 乔木高度 $(\mathrm{m}) ; W_{\mathrm{B}}$, 乔木枝生物量 $(\mathrm{kg}) ; W_{\mathrm{L}}$, 乔木叶生物量 $(\mathrm{kg}) ; W_{\mathrm{R}}$, 乔木根生物量 $(\mathrm{kg}) ; W_{\mathrm{S}}$, 乔木干生物量 $(\mathrm{kg})$ 。

$D$, tree diameter $(\mathrm{cm}) ; H$, tree height $(\mathrm{m}) ; W_{\mathrm{B}}$, tree branch biomass $(\mathrm{kg}) ; W_{\mathrm{L}}$, tree leaf biomass $(\mathrm{kg}) ; W_{\mathrm{R}}$, tree root biomass $(\mathrm{kg}) ; W_{\mathrm{S}}$, tree stem biomass $(\mathrm{kg})$.

表2 青藏高原高寒区阔叶林不同林型龄级与龄组划分表

Table 2 The partition table of age classes for different broad-leaved forests in the alpine region of the Qinghai-Xizang Plateau

\begin{tabular}{|c|c|c|c|c|c|}
\hline $\begin{array}{l}\text { 林型 } \\
\text { Forest type }\end{array}$ & $\begin{array}{c}\text { 幼龄林 } \\
\text { Young forest }\end{array}$ & $\begin{array}{c}\text { 中龄林 } \\
\text { Middle-aged forest }\end{array}$ & $\begin{array}{c}\text { 近熟林 } \\
\text { Near-mature forest } \\
\end{array}$ & $\begin{array}{c}\text { 成熟林 } \\
\text { Mature Forest }\end{array}$ & $\begin{array}{c}\text { 过熟林 } \\
\text { Over-mature forest }\end{array}$ \\
\hline 栋类 Quercus spp. & $\leqslant 40$ & $41-60$ & $61-80$ & $81-120$ & $\geqslant 121$ \\
\hline 桦木 Betula spp. & $\leqslant 30$ & $31-50$ & $51-60$ & $61-80$ & $\geqslant 81$ \\
\hline 杨树 Populus spp. & $\leqslant 10$ & $11-15$ & $16-20$ & $21-30$ & $\geqslant 31$ \\
\hline 其他软阔类 Other soft broad-leaved species & $\leqslant 10$ & $11-15$ & $16-20$ & $21-30$ & $\geqslant 31$ \\
\hline 其他硬阔类 Other hard broad-leaved species & $\leqslant 40$ & $41-60$ & $61-80$ & $81-120$ & $\geqslant 121$ \\
\hline 阔叶混交林 Broad-leaved mixed forest & $\leqslant 40$ & $41-60$ & $61-80$ & $81-120$ & $\geqslant 121$ \\
\hline
\end{tabular}

系统单位面积碳储量 $\left(\mathrm{Mg} \cdot \mathrm{hm}^{-2}\right) ; A_{\mathrm{F}, i,}$ 为第 $i$ 种阔叶林 类型第 $j$ 个林龄的分布面积 $\left(\mathrm{hm}^{2}\right)$ 。

\subsection{2 固碳速率的估算}

基于 3 次森林清查资料和样地调查资料估算的 碳储量结果, 通过不同时期阔叶林植被碳储量变化 量来估算固碳速率 $\left(\Delta C_{\mathrm{F}}, \mathrm{Mg} \cdot \mathrm{hm}^{-2} \cdot \mathrm{a}^{-1}\right)$ 。

$$
\Delta C_{\mathrm{F}}=\frac{\left(C_{\mathrm{F} t_{2}}-C_{\mathrm{Ft}}\right)}{\left(t_{2}-t_{1}\right)}
$$

式中 $C_{\mathrm{F}_{1}} 、 C_{\mathrm{F}_{2}}$ 分别为 $t_{1} 、 t_{2}$ 时间的碳储量 $\left(\mathrm{Mg} \cdot \mathrm{hm}^{-2}\right)$ 。

\subsection{3 固碳潜力的估算}

固碳潜力可以用理论最大固碳潜力和相对固 碳潜力 $\left(\mathrm{Mg} \cdot \mathrm{hm}^{-2}\right)$ 来表示。本研究估算的固碳潜力为 阔叶林理论最大固碳潜力, 根据森林演替理论选择 演替顶级自然林作为该类自然林生态系统理论最 大固碳潜力的参照系来估算固碳潜力(Sleutel et al., 2003)。
阔叶林固碳潜力=演替顶级阔叶林碳密度-阔 叶林平均碳密度

\section{2 结果和分析}

\section{1 青藏高原高寒区阔叶林植被固碳现状}

\subsection{1 不同林型固碳现状}

青藏高原高寒区阔叶林植被平均碳密度为 $89.04 \mathrm{Mg} \cdot \mathrm{hm}^{-2}$, 植被各层碳密度大小顺序为: 乔木 层 $\left(83.04 \mathrm{Mg} \cdot \mathrm{hm}^{-2}\right)$ > 灌木层 $\left(4.40 \mathrm{Mg} \cdot \mathrm{hm}^{-2}\right)$ >调落物 层 $\left(1.13 \mathrm{Mg} \cdot \mathrm{hm}^{-2}\right)>$ 草本层 $\left(0.40 \mathrm{Mg} \cdot \mathrm{hm}^{-2}\right)>$ 枯死木 层 $\left(0.07 \mathrm{Mg} \cdot \mathrm{hm}^{-2}\right)$ 。不同阔叶林类型乔木层、灌木层、 草本层、调落物层和枯死木层碳密度分别在63.47$92.80 、 1.57-15.76 、 0.13-1.81 、 0.28-3.76$ 和 $0-1.55$ $\mathrm{Mg} \cdot \mathrm{hm}^{-2}$ 之间, 植被碳密度在68.74-102.86 $\mathrm{Mg} \cdot \mathrm{hm}^{-2}$ 之间(图2A)。乔木层中碳密度最大和最小林型分别 是阔叶混交林和桦木林, 灌木层中碳密度最大和 最小林型分别是栋类林和阔叶混交林; 草本层碳 
密度为桦木林最大, 其他软阔林最小; 调落物层 碳密度为其他硬阔林最大, 阔叶混交林最小; 除 桦木林和杨树林外，其余林型均没有发现枯死木。 植被碳密度为其他硬阔林最大, 其他软阔林最小。

青藏高原高寒区阔叶林植被碳储量为 310.70 $\mathrm{Tg}$, 其中乔木层、灌木层、草本层、调落物层和枯 死木层分别占植被碳储量的 $93.27 \% 、 4.94 \% 、 0.45 \%$ 、 $1.27 \%$ 和 $0.08 \%$, 各层碳储量大小排序为: 乔木层 $(289.77 \mathrm{Tg})>$ >灌木层 $(15.35 \mathrm{Tg})>$ >调落物层 $(3.93 \mathrm{Tg})$ $>$ 草本层 $(1.39 \mathrm{Tg})>$ 枯死木层 $(0.26 \mathrm{Tg})$ 。不同森林类 型乔木层、灌木层、草本层、调落物层和枯死木层 碳储量分别在5.93-207.57、0.35-8.73、0.02-0.47、 0.05-1.96和0-0.24 Tg之间, 植被碳储量在6.35$212.17 \mathrm{Tg}$ 之间(图2B)。阔叶混交林碳储量最大, 其
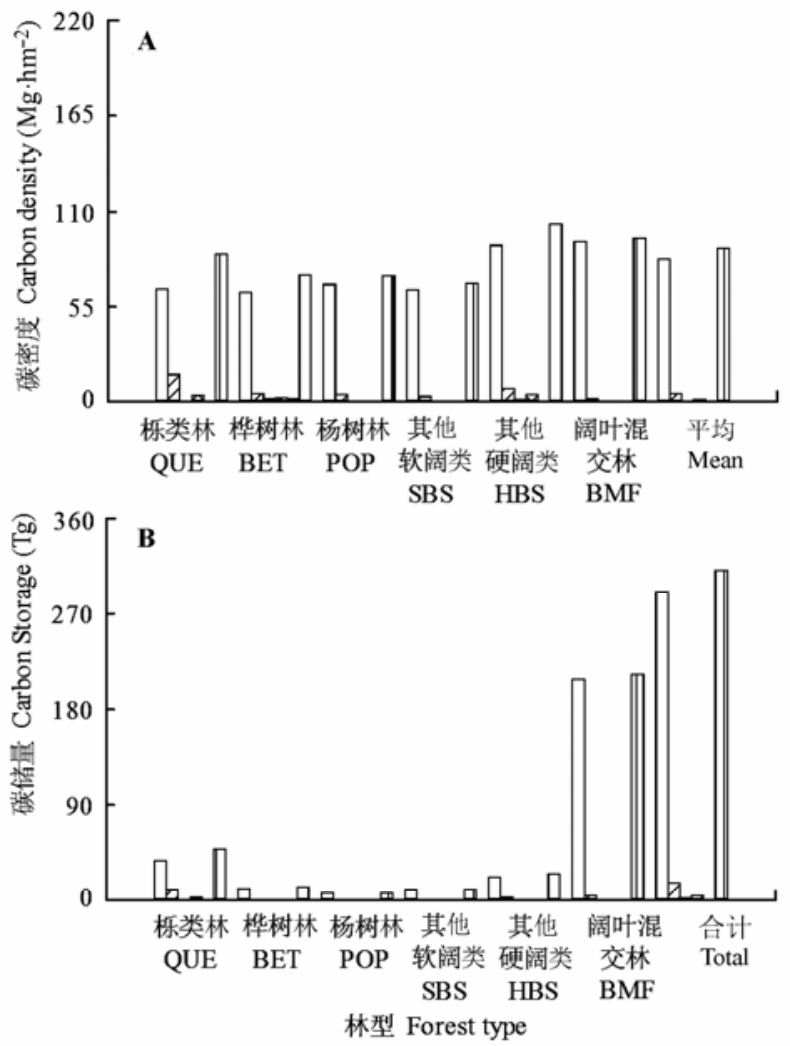

\footnotetext{
口乔木层 Tree layer [ 草本层 Grass layer
}

次是柇类林，其碳储量分别占阔叶林碳储量的 $68.29 \%$ 和 $15.26 \%$ 。

\subsection{2 不同龄级乔木层固碳现状}

青藏高原高寒区阔叶林植被主要为近熟林和 成熟林, 碳储量表现为成熟林最大, 占阔叶林乔木 层碳储量的 $38.85 \%$, 近熟林略低于成熟林, 占 $38.68 \%$ (图3B)。幼龄林、中龄林、近熟林、成熟林 和过熟林的碳密度分别介于13.28-30.25、35.65$68.21 、 65.60-102.82 、 63.55-114.64$ 和74.97-138.74 $\mathrm{Mg} \cdot \mathrm{hm}^{-2}$ 之间(图3A)。各龄组中过熟林碳密度最大 林型为阔叶混交林, 其余龄组碳密度最大的林型均 为其他硬阔林, 碳密度最小的林型均为桦木林。林 龄组成对乔木层碳密度影响较大, 阔叶林6类林型 碳密度多数表现为幼龄林最小, 且随林龄增加碳密
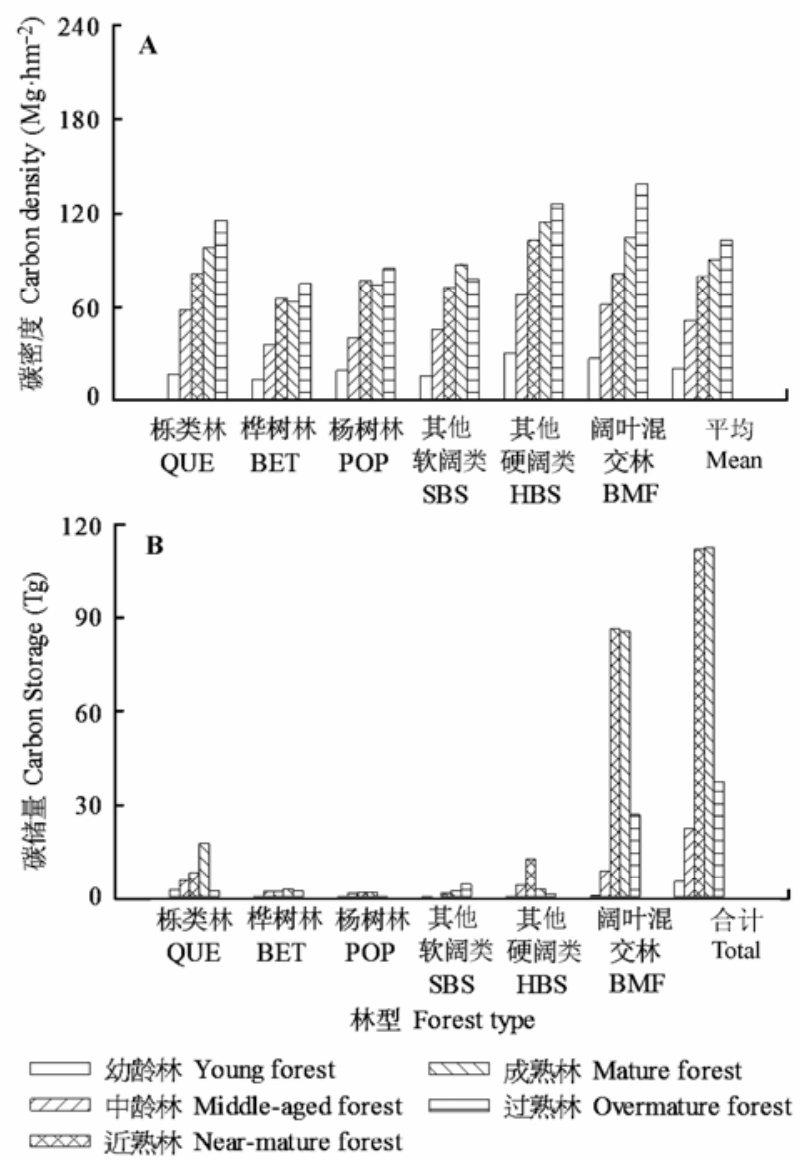

图3 青藏高原高寒区阔叶林不同龄级乔木层碳储量和碳密 度。

Fig. 3 Carbon storage and density of overstory tree layer for different age classes in the broad-leaved forests in the alpine region of the Qinghai-Xizang Plateau. QUE, BET, POP, SBS, HBS, BMF see Fig. 2.
图2 青藏高原高寒区阔叶林乔木层、灌木层、草本层、调 落物层、枯死木层和植被碳储量和碳密度。

Fig. 2 Carbon storage and density of overstory, understory, grass, litter, dead woody layers in the broad-leaved forests in the alpine region of the Qinghai-Xizang Plateau. QUE, BET, POP, SBS, HBS, BMF refer to Quercus forest, Betula forest, Populus forest, other soft broad-leaved species, other hard broad-leaved species, broad-leaved mixed forest, respectively. 
度有增大的趋势(图3A)。

\section{2 青藏高原高寒区阔叶林植被固碳速率}

\subsection{1 不同林型固碳速率}

三次森林资源连续清查阔叶林植被碳储量分 别为304.26、306.44和310.70 Tg, 平均每年固碳量为 $0.64 \mathrm{Tg} \cdot \mathrm{a}^{-1}, 5$ 年期间隔固碳速率分别为 $0.13 、 0.25$ $\mathrm{Mg} \cdot \mathrm{hm}^{-2} \cdot \mathrm{a}^{-1}$, 平均为 $0.19 \mathrm{Mg} \cdot \mathrm{hm}^{-2} \cdot \mathrm{a}^{-1}$ (表3)。2011年 阔叶林各林型植被碳储量大小分别为阔叶混交林 (212.17 Tg) >栋类林(47.42 Tg) >其他硬阔林(23.86 $\mathrm{Tg})>$ 桦木林 $(11.56 \mathrm{Tg})>$ 其他软阔林 $(9.33 \mathrm{Tg})>$ 杨树 林(6.35 Tg), 阔叶混交林历次调查的碳储量均最高, 分别占3次调查阔叶林碳储量的 $69.68 \% 、 69.16 \%$ 和 $68.29 \%$, 但其 10 年平均年固碳量 $\left(0.02 \mathrm{Tg} \cdot \mathrm{a}^{-1}\right)$ 和固 碳速率 $\left(0.01 \mathrm{Mg} \cdot \mathrm{hm}^{-2} \cdot \mathrm{a}^{-1}\right)$ 在不同林型中较小。其次 是柇类林, 分别占 3 次调查阔叶林总碳储量的 $14.68 \% 、 14.87 \%$ 和 $15.26 \%$, 其10年平均年固碳量 $\left(0.28 \mathrm{Tg} \cdot \mathrm{a}^{-1}\right)$ 在不同林分中最大。杨树林历次调查碳 储量最低, 占3次调查阔叶林碳储量的 $1.80 \% 、 1.96 \%$ 和 $2.04 \%$, 其 10 年平均年固碳量和固碳速率分别为 $0.09 \mathrm{Tg} \cdot \mathrm{a}^{-1}$ 和 $0.74 \mathrm{Mg} \cdot \mathrm{hm}^{-2} \cdot \mathrm{a}^{-1}$ 。 10 年间除其他
硬阔林固碳量为负增长外, 其余林型均增长。

\subsection{2 不同龄级乔木层固碳速率}

三次森林资源连续清查阔叶林乔木层碳储量 分别为284.53、286.18和289.77 Tg, 平均年固碳量为 $0.52 \mathrm{Tg} \cdot \mathrm{a}^{-1}, 5$ 年期间隔固碳速率分别为 0.15 和 0.32 $\mathrm{Mg} \cdot \mathrm{hm}^{-2} \cdot \mathrm{a}^{-1}$, 平均为 $0.24 \mathrm{Mg} \cdot \mathrm{hm}^{-2} \cdot \mathrm{a}^{-1}$ (表 4$)$ 。除2001 年近熟林碳储量略高于成熟林外, 各龄组乔木层碳 储量分别为成熟林 $>$ 近熟林 $>$ 过熟林 $>$ 中龄林 $>$ 幼龄 林, 历次调查近熟林和成熟林固碳量最大, 其总和 均占乔木层固碳量的 $75 \%$ 以上。此外, 阔叶林各龄 组乔木层碳储量随时间表现为逐渐增加趋势。其中, 成熟林固碳速率最大, 10 年期间隔为 $0.95 \mathrm{Mg} \cdot \mathrm{hm}^{-2}$. $\mathrm{a}^{-1}$, 平均年固碳量 $0.10 \mathrm{Tg} \cdot \mathrm{a}^{-1}$; 幼龄林固碳速率最 小, 10 年期间隔为 $0.30 \mathrm{Mg} \cdot \mathrm{hm}^{-2} \cdot \mathrm{a}^{-1}$, 平均年固碳量 $0.15 \mathrm{Tg} \cdot \mathrm{a}^{-1}$ 。各林龄组固碳速率均表现为正, 主要是 因为近年森林保护工程的开展使阔叶林生长健康 和自然演替更新良好。

\section{3 青藏高原阔叶林植被乔木层固碳潜力}

2011年阔叶林乔木层固碳潜力为 $19.09 \mathrm{Mg}$. $\mathrm{hm}^{-2}$ 。各林分乔木层固碳潜力分别为柇类(49.88 Mg.

表3 青藏高原高寒区阔叶林不同林分碳储量和固碳速率

Table 3 The carbon storage and its rate of different broad-leaved forests in the alpine region of the Qinghai-Xizang Plateau

\begin{tabular}{|c|c|c|c|c|c|c|c|}
\hline \multirow[t]{2}{*}{$\begin{array}{l}\text { 林型 } \\
\text { Forest type }\end{array}$} & \multicolumn{3}{|c|}{$\begin{array}{c}\text { 固碳速率 } \\
\text { Carbon sequestration rate }\left(\mathrm{Mg} \cdot \mathrm{hm}^{-2} \cdot \mathrm{a}^{-1}\right)\end{array}$} & \multicolumn{3}{|c|}{$\begin{array}{c}\text { 碳储量 } \\
\text { Carbon storage (Tg) }\end{array}$} & \multirow{2}{*}{$\begin{array}{c}\text { 10年平均年固碳量 } \\
\text { Mean annual carbon } \\
\text { sequestration of ten } \\
\text { years }\left(\mathrm{Tg} \cdot \mathrm{a}^{-1}\right)\end{array}$} \\
\hline & 2001-2006 & 2006-2011 & 2001-2011 & 2001 & 2006 & 2011 & \\
\hline 栎类 Quercus & 0.36 & 0.74 & 0.55 & 44.66 & 45.56 & 47.42 & 0.28 \\
\hline 桦木 Betula & 1.04 & 0.71 & 0.88 & 10.00 & 10.92 & 11.56 & 0.16 \\
\hline 杨树 Populus & 0.92 & 0.57 & 0.74 & 5.46 & 6.01 & 6.35 & 0.09 \\
\hline 其他软阔类 Other soft broad-leaved species & -0.24 & 2.65 & 1.21 & 8.14 & 8.03 & 9.33 & 0.12 \\
\hline 其他硬阔类 Other hard broad-leaved species & 0.01 & -0.12 & -0.06 & 23.99 & 24.00 & 23.86 & -0.01 \\
\hline 阔叶混交林 Broad-leaved mixed forest & -0.01 & 0.02 & 0.01 & 212.00 & 211.92 & 212.17 & 0.02 \\
\hline 全部林型 All forest types & 0.13 & 0.25 & 0.19 & 304.26 & 306.44 & 310.70 & 0.64 \\
\hline
\end{tabular}

表4 青藏高原高寒区阔叶林不同龄级碳储量和固碳速率

Table 4 The carbon storage and its rate for different age classes of the broad-leaved forests in the alpine region of the Qinghai-Xizang Plateau

\begin{tabular}{|c|c|c|c|c|c|c|c|}
\hline \multirow[t]{2}{*}{$\begin{array}{l}\text { 龄级 } \\
\text { Age class }\end{array}$} & \multicolumn{3}{|c|}{$\begin{array}{c}\text { 固碳速率 } \\
\text { Carbon sequestration rate }\left(\mathrm{Mg} \cdot \mathrm{hm}^{-2} \cdot \mathrm{a}^{-1}\right) \\
\end{array}$} & \multicolumn{3}{|c|}{$\begin{array}{c}\text { 碳储量 } \\
\text { Carbon storage (Tg) } \\
\end{array}$} & \multirow{2}{*}{$\begin{array}{c}\text { 10年平均年固碳量 } \\
\text { Mean annual carbon } \\
\text { sequestration of ten years } \\
\left(\mathrm{Tg} \cdot \mathrm{a}^{-1}\right)\end{array}$} \\
\hline & 2001-2006 & $2006-2011$ & 2001-2011 & 2001 & 2006 & 2011 & \\
\hline 幼龄林 Young forest & 0.14 & 0.47 & 0.30 & 3.92 & 4.26 & 5.44 & 0.15 \\
\hline 中龄林 Middle-aged forest & 0.82 & 0.47 & 0.65 & 21.16 & 21.89 & 22.31 & 0.12 \\
\hline 近熟林 Near-mature forest & 0.05 & 0.88 & 0.47 & 111.65 & 111.68 & 112.10 & 0.04 \\
\hline 成熟林 Mature Forest & 0.47 & 1.43 & 0.95 & 111.57 & 111.83 & 112.59 & 0.10 \\
\hline 过熟林 Over-mature forest & 0.26 & 0.71 & 0.49 & 36.22 & 36.52 & 37.34 & 0.11 \\
\hline 全部龄级 All age classes & 0.15 & 0.32 & 0.24 & 284.53 & 286.18 & 289.77 & 0.52 \\
\hline
\end{tabular}


$\mathrm{hm}^{-2}$ ) >阔叶混交林(45.94 Mg.hm ${ }^{-2}$ ) >杨树林(37.74 $\left.\mathrm{Mg} \cdot \mathrm{hm}^{-2}\right)>$ 其他硬阔林 $\left(35.20 \mathrm{Mg} \cdot \mathrm{hm}^{-2}\right)>$ 其他软阔 林(30.87 Mg.hm $\left.{ }^{-2}\right)>$ 桦木林(12.27 $\mathrm{Mg} \cdot \mathrm{hm}^{-2}$ ) (图4)。

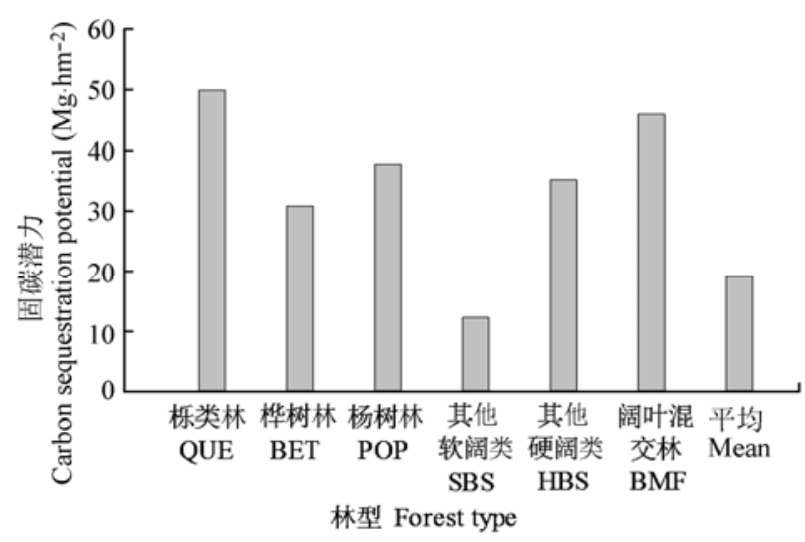

图4 青藏高原高寒区阔叶林不同林型固碳潜力。

Fig. 4 The carbon sequestration potential of different broadleaved forests in alpine region of the Qinghai-Xizang Plateau. QUE, BET, POP, SBS, HBS, BMF see Fig. 2.

\section{3 讨论}

\section{1 青藏高原阔叶林在全国森林碳汇中的地位}

森林作为陆地生态系统的主体, 其碳储量在稳 定全球气候变化、减缓温室效应等方面发挥着重要 的作用。Piao等(2005)估测我国阔叶林和森林植被 碳储量分别为 2.46-2.62 和 5.62-5.99 Pg, Guo 等 (2010)估测分别为2.93-3.57和5.86-7.73 Pg, Fang和 Wang (2001)估测分别为1.91-4.54和3.78-6.86 Pg。 本研究估测青藏高原高寒区阔叶林植被碳储量为 $310.70 \mathrm{Tg}$, 占全国阔叶林植被碳储量的 6.84\%$16.27 \%$, 占全国森林植被碳储量的 $4.53 \%-8.22 \%$ 。 本研究中阔叶林植被碳密度为 $89.04 \mathrm{Mg} \cdot \mathrm{hm}^{-2}$, 高于 全国阔叶林平均碳密度 $\left(40.18 \mathrm{Mg} \cdot \mathrm{hm}^{-2}\right.$ )水平(中华 人民共和国建设部，1993), 而与青藏高原高寒区处 于同一林区的四川省和云南省阔叶林碳密度分别 为 $30.35 \mathrm{Mg} \cdot \mathrm{hm}^{-2}$ (唐霄, 2007)和66.50 $\mathrm{Mg} \cdot \mathrm{hm}^{-2}$ (李 亮, 2012), 我国东北林区的吉林省和东南林区的广 东省同期内阔叶林碳密度分别为 $49.55 \mathrm{Mg} \cdot \mathrm{hm}^{-2}$ (王 新闯等, 2011)和21.56 Mg.hm ${ }^{-2}$ (叶金盛和余光辉, 2010), 均小于青藏高原高寒区阔叶林碳密度。这主 要是由于青藏高原高寒区阔叶林中碳密度较大的 近熟林和成熟林所占比重大所致(面积共占阔叶林 的70.85\%)。一方面, 较大的碳密度使阔叶林具有相
当可观的碳库, 另一方面, 近熟林和成熟林比重过 大的阔叶林龄级结构使研究区阔叶林的固碳速率 可能偏低。近10年青藏高原高寒区阔叶林固碳速率 为 $0.19 \mathrm{Mg} \cdot \mathrm{hm}^{-2} \cdot \mathrm{a}^{-1}$, 低于同位于西南林区的四川省 (包括重庆市)阔叶林固碳速率(1993-2003年，0.29 $\mathrm{Mg} \cdot \mathrm{hm}^{-2} \cdot \mathrm{a}^{-1}$, 黄从德等, 2008), 但仍高于东南林区 的广东省阔叶林固碳速率(1997-2007年，0.091 $\mathrm{Mg} \cdot \mathrm{hm}^{-2} \cdot \mathrm{a}^{-1}$, 叶金盛和余光辉, 2010)。此外, 该地区 近10年阔叶林固碳潜力为 $19.09 \mathrm{Mg} \cdot \mathrm{hm}^{-2}$, 略高于东 北林区的吉林省阔叶林固碳潜力 (17.63 $\mathrm{Mg} \cdot \mathrm{hm}^{-2}$, 王新闯等, 2011), 略低于同位于西南林区的四川省 阔叶林固碳潜力(19.39 Mg.hm ${ }^{-2}$, 黄从德, 2008)。可 见, 青藏高原高寒区阔叶林在全国森林中具有较强 的碳汇功能, 在全国森林碳储量中扮演着重要的角 色。

\section{2 阔叶林植被碳储量、速率和潜力的影响因素}

林龄对阔叶林碳密度、碳储量、固碳速率和固 碳潜力的影响很大。任治忠对我国西南桦固碳量与 林龄关系的研究发现, 西南华乔木林碳密度与林龄 间呈二次抛物线模型关系(任治忠，2013)。甄伟等 (2014)研究发现辽宁省柇类在林龄约为 80 年时达到 成熟, 成熟以后其蓄积量变化不大, 碳储量也逐渐 趋于稳定。在研究吉林省森林植被碳储量现状时, 5 类阔叶林乔木层碳密度多数表现为过熟林最大, 幼 龄林最小(王新闯等, 2011)。林龄通过影响碳密度进 一步影响阔叶林碳储量、固碳速率及其固碳潜力。 本研究中, 林龄组成对乔木层碳密度影响很大, 阔 叶林6类林型碳密度多数表现为幼龄林最小, 且随 林龄增加碳密度有增大的趋势, 但由于各龄级面积 差异较大, 碳储量最大龄级集中在近熟林和成熟 林; 固碳速率则表现为成熟林最大, 幼龄林最小。

地形、坡度和海拔等环境因子是阔叶林固碳的 重要影响因素。环境因子不同, 其所处水分、养分、 光照和土壤条件不同, 阔叶林碳密度、碳储量、固 碳速率及潜力也存在很大差异。在研究大兴安岭森 林生物量影响因素时, 落叶阔叶混交林碳密度表现 为随海拔升高先增大后减小且阳坡大于阴坡的特 征(王晓莉等，2014a，2014b); 王媛认为坡度越大， 碳密度越大(王媛, 2014)。本研究中由于受调查样点 数的限制, 未能考虑坡向、坡度和海拔等环境因子 对阔叶林固碳的影响, 但就全区调查的阔叶林而 言, 以高山栋为例, 植被碳密度总体表现出随海拔 
升高而减小、随坡度增加而增大，阳坡大于阴坡的 特征。

此外, 森林砍伐或培育引起的阔叶林面积减少 或增加也是影响区域阔叶林植被碳储量变化的重 要原因。从研究区的固碳速率来看, 个别林型也表 现出因砍伐引起面积减少而导致其植被碳储量减 少的结果(表3)。比如其他软阔林在2001-2006年间 砍伐严重, 其固碳速率为 $-0.24 \mathrm{Mg} \cdot \mathrm{hm}^{-2} \cdot \mathrm{a}^{-1}$; 其他 硬阔林在2006-2011年间砍伐严重, 固碳速率为 $-0.12 \mathrm{Mg} \cdot \mathrm{hm}^{-2} \cdot \mathrm{a}^{-1}$ 。虽然个别林型存在砍伐现象, 但 总体上阔叶林植被碳储量表现出逐年增加的趋势, 分析原因除了阔叶林自身生长状况良好外, 还与近 年来林业保护工程对研究区中幼龄林栽种培育息 息相关。因此, 减少滥砍滥伐, 大量栽种和培育中 幼龄林, 增加阔叶林面积, 有利于提升研究区阔叶 林资源在全国碳汇中的作用。

\section{3 估算结果的不确定性}

不同学者所采用的估算方法不同造成对森林 植被碳储量的估算结果差异较大。就国家尺度而言, Pan等(2004)利用改进的生物量-蓄积量方法估算了 20年来(1973-1993年)中国森林碳储量和固碳速率, 碳储量低于Fang和Wang (2001)的估算结果, 而固 碳速率则高于Fang和Wang (2001)的估算结果。王效 科等(2001)基于561个样地资料估算了中国森林碳 储量, 与Pan等(2004)的估算结果较为一致。就区域 尺度而言, 黄从德(2008)利用四川省各县森林清查 资料估算了四川省森林植被生物量, 比唐霄(2007) 的估算结果低 $12.97 \%$, 而与赵敏和周广胜(2004)的 估算结果基本一致。若基于桂来庭(2013)和卢航等 (2013)的估算结果, 青藏高原高寒区森林植被碳储 量为914.2 Tg, 远高于王效科等(2001)的估算结果 (246.08 Tg), 而与吴庆标等(2008)的估算结果基本 一致(904.33-987.93 Tg)。本研究没有估算青藏高原 高寒区全部植被碳储量, 仅对阔叶林植被碳储量进 行了估算, 其值在2011年达310.70 Tg, 如以桂来庭 (2013)和吴庆标等(2008)的研究结果为基础, 青藏 高原高寒区阔叶林植被碳储量占整个森林的 31.45\%-34.36\%, 与青藏高原高寒区阔叶林蓄积量 比例(21.02\%)相比, 阔叶林碳储量比例偏高。分析 原因可能是因为桂来庭(2013)和卢航等(2013)在估 算植被碳储量时均没有充分考虑林下植被碳储量 (包括灌草层、调落物和枯死木层), 而吴庆标等
(2008)在估算植被碳储量时所采用的林木碳密度 (全国平均密度)可能低于青藏高原高寒区植被碳密 度, 使其对青藏高原高寒区森林植被碳储量估算偏 低。张万林等(2013)和付达夫(2014)分别估算了西藏 自治区凋落物和灌木碳储量, 其值高达 $204 \mathrm{Tg}$ 和73 $\mathrm{Tg}$ 。从以上分析可以看出, 以往结果并未全面考虑 整个植被层, 导致青藏高原高寒区森林碳储量的估 算结果偏低。因此, 在估算区域碳储量时, 不仅森 林生物量模型对森林植被碳储量估算结果影响很 大, 而且估算参数的精确性和估算对象的完整性同 样对估算结果影响很大。

此外, 龄级随时间的推移引起的碳密度变化也 增加了阔叶林固碳速率估算的不确定性。三次森林 资源清查间隔为 10 年, 期间会引起阔叶林部分林型 从低龄级变为高龄级, 碳密度、碳储量和固碳速率 也会随之发生相应的变化。然而, 10年的时间仅能 判定杨树林和软阔类林更新了一个或两个龄级, 无 法准确判定阔叶林其余林型龄级更新状况(表2), 因 此无法用定量的方法来估算龄级更新引起的碳密 度和固碳速率的变化。考虑到研究区杨树林和其他 软阔林碳储量之和仅占阔叶林碳储量的 $6.2 \%$, 其龄 级更新引起的碳密度变化对阔叶林固碳速率的影 响不大, 本研究在估算固碳速率时, 没有考虑 10 年 前后龄级更新引起的碳密度变化。但对于优势树种 为杨树和其他软阔的省区, 或者针对超过 40 年的长 期的固碳速率的估算, 龄级的更新引起的固碳速率 的变化就不能被忽略。因此, 如何准确定量龄级更 新引起的固碳速率的变化对于准确估算森林固碳 速率有着重要的意义。

\section{4 结论}

本研究根据森林连续清查资料和样地实测数 据估算了青藏高原高寒区阔叶林植被的碳密度、碳 储量、固碳速率和固碳潜力。研究结果表明阔叶林 植被碳储量和碳密度分别为 $310.70 \mathrm{Tg}$ 和 89.04 $\mathrm{Mg} \cdot \mathrm{hm}^{-2}$, 高于全国多数省区阔叶林碳储量和碳密 度, 其中以阔叶混交林碳储量最大, 其他硬阔林碳 密度最大。近年来森林保护工程广泛开展, 10年间 阔叶林植被碳储量逐渐增加, 其中以其他软阔林和 成熟林增幅最大。研究区阔叶林中幼龄林比重偏小, 其固碳速率和乔木层固碳潜力偏小。因此, 要提升 研究区阔叶林资源在全球碳平衡和碳循环中的作 
用以及在区域生态建设中的作用，一方面应加强森 林监管力度, 杜绝对阔叶林的滥砍滥伐, 使其健康 良好生长, 增加森林碳汇潜力, 另一方面, 应以保 护和培育中幼龄林为中心, 通过科学抚育提高中幼 龄林的碳汇能力。

基金项目 中国科学院战略性先导科技专项 (XDA05050207)和中国科学院重点部署项目-创新 团队国际合作伙伴计划(KZZD-EW-TZ-06)。

致谢 感谢青海省和西藏自治区林业厅和各市林业 部门在野外采样调查工作中的支持和配合。

\section{参考文献}

Akselsson C, Berg B, Meentemeyer V, Westling O (2005). Carbon sequestration rates in organic layers of boreal and temperate forest soils-Sweden as a case study. Global Ecology and Biogeography, 14, 77-84.

Cai LS (2009). Study on Carbon Storage of Forest Vegetation and Its Changes in Yunnan Province. Master degree dissertation, Southwest Forestry University, Kunming. 28-29. (in Chinese with English abstract) [蔡丽莎 (2009). 云南 省森林植被碳储量及动态变化研究. 硕士学位论文, 西 南林学院, 昆明. 28-29.]

Dixon RK, Solomon AM, Brown S, Houghton RA, Trexier MC, Wisniewski J (1994). Carbon pools and flux of global forest ecosystems. Science, 263, 185-190.

Fang JY, Wang ZM (2001). Forest biomass estimation at regional and global levels, with special reference to China's forest biomass. Ecological Research, 16, 587-592.

Fu DF (2014). Shrubwood carbon reserve estimation in Tibet Autonomous Region. Central South Forest Inventory and Planning, 33(4), 4-7. (in Chinese with English abstract) [付达夫 (2014). 西藏自治区灌木林碳储量估算. 中南 林业调查规划, 33(4), 4-7.]

Ge LW, Pan G, Ren DZ, Du YJ, Zheng XL (2013). Forest carbon storage, carbon density, and their distribution characteristics in Linzhi area of Tibet, China. Chinese Journal of Applied Ecology, 24, 319-325. (in Chinese with English abstract) [ 葛立雯, 潘刚, 任德智, 杜玉婕, 郑祥蕾 (2013). 西藏林芝地区森林碳储量、碳密度及其分布. 应 用生态学报, 24, 319-325.]

Ge ZM, Kellomäki S, Peltola H, Zhou X, Väisänen H, Strandman $H$ (2013). Impacts of climate change on primary production and carbon sequestration of boreal Norway spruce forests: Finland as a model. Climatic Change, 118, 259-273.

General Administration of Quality Supervision, Inspection, Quarantine of the People's Republic of China, Standardization Administration of the People's Republic of China (2011). GB/T 26424-2010 Technical Regulations for In- ventory for Forest Management Planning and Design. China Standard Publishing House, Beijing. 8. (in Chinese with English abstract) [中华人民共和国国家质量监督检 验检疫总局, 中国国家标准化管理委员会 (2011). GB/T 26424-2010森林资源规划设计调查技术规程. 中 国标准出版社, 北京. 8.]

Gui LT (2013). The status and countermeasures of Tibet forest carbon pool. Central South Forest Inventory and Planning, 32(3), 1-4. (in Chinese with English abstract) [桂来庭 (2013). 西藏自治区森林碳库状况及对策. 中南林业调 查规划, 32(3), 1-4.]

Guo ZD, Fang JY, Pan YD, Birdsey R (2010). Inventory-based estimates of forest biomass carbon stocks in China: A comparison of three methods. Forest Ecology and Management, 259, 1225-1231.

Huang CD (2008). Characteristics of Carbon Stock and Its Spatial Differentiation in the Forest Ecosystem of Sichuan. $\mathrm{PhD}$ dissertation, Sichuan Agricultural University, Yaan. 90-91. (in Chinese with English abstract) [黄从德 (2008). 四川森林生态系统碳储量及其空间分异特征. 博士学 位论文, 四川农业大学, 雅安. 90-91.]

Huang CD, Zhang J, Yang WQ, Tang X, Zhao AJ (2008). Dynamics on forest carbon stock in Sichuan Province and Chongqing City. Acta Ecologica Sinica, 28, 966-975. (in Chinese with English abstract) [黄从德, 张健, 杨万勤, 唐宵, 赵安㺵 (2008). 四川省及重庆地区森林植被碳储 量动态. 生态学报, 28, 966-975.]

Huang M, Ji JJ, Peng LL (2008). The response of vegetation net primary productivity to climate change during 1981-2000 in the Tibetan Plateau. Climatic and Environmental Research, 13, 608-616. (in Chinese with English abstract) [黄玫, 季劲钧, 彭莉莉 (2008). 青藏高原1981 2000年 植被净初级生产力对气候变化的响应. 气候与环境研 究, 13, 608-616.]

Li KR, Wang SQ, Cao MK (2004). Vegetation and soil carbon storage in China. Science in China (Series D: Earth Sciences), 47, 49-57.

Li L (2012). Change of Carbon Storage in Forest Vegetation and Carbon Sequestration Potential Analysis of Yunnan Province in 1992-2007. Master degree dissertation, Yunnan University of Finance and Economics, Kunming. 22-23. (in Chinese with English abstract) [李亮 (2012). 云南省1992-2007年森林植被碳储量动态变化及其碳汇 潜力分析. 硕士学位论文, 云南财经大学, 昆明. 22-23.]

Lin H, Ma X, He ZH, Liu B, Huang Z, Tian XJ (2014). Research on forest ecosystem carbon sinks in Jiangsu Province. Forest Resources Management, (1), 89-97. (in Chinese with English abstract) [林虹, 马旭, 何再华, 刘斌, 黄众, 田兴军 (2014). 江苏省森林生态系统碳汇现状研

www.plant-ecology.com 
究. 林业资源管理, (1), 89-97.]

Lu H, Liu K, Wu JH (2013). Change of carbon storage in forest vegetation and current situation analysis of Qinghai pronvince in reccent 20 years. Resources and Environment in the Yangtze Basin, 22, 1333-1338. (in Chinese with English abstract) [卢航, 刘康, 吴金鸿 (2013). 青海省近20 年森林植被碳储量变化及其现状分析. 长江流域资源 与环境, 22, 1333-1338.]

Luo TX (1996). Patterns of Net Primary Productivity for Chinese Major Forest Types and Their Mathematical Models. $\mathrm{PhD}$ dissertation, Institute of Geographic Sciences and Natural Resources Research, Chinese Academy of Sciences, Beijing. 132-167. (in Chinese with English abstract) [罗天祥 (1996). 中国主要森林类型生物生产力 格局及其数学模型. 博士学位论文, 中国科学院研究生 院, 北京. 132-167.]

Malhi Y, Baldocchi DD, Jarvis PG (1999). The carbon balance of tropical, temperate and boreal forests. Plant, Cell \& Environment, 22, 715-740.

Matsuzaki E, Sanborn P, Fredeen AL, Shaw CH, Hawkins C (2013). Carbon stocks in managed and unmanaged old-growth western redcedar and western hemlock stands of Canada's inland temperate rainforests. Forest Ecology and Management, 297, 108-119.

Ministry of Construction of the People's Republic of China (1993). City Green Regulations Interpretation. Chinese Legal Press, Beijing. (in Chinese with English abstract) [中华人民共和国建设部 (1993). 城市绿化条例释义. 中国法制出版社, 北京.]

$\mathrm{Ni} \mathrm{J}$ (2002). Effects of climate change on carbon storage in boreal forests of China: A local perspective. Climatic Change, 55, 61-75.

Pan YD, Luo TX, Birdsey R, Hom J, Melillo J (2004). New estimates of carbon storage and sequestration in China's forests: Effects of age-class and method on inventorybased carbon estimation. Climatic Change, 67, 211-236.

Piao SL, Fang JY, Zhu B, Tan K (2005). Forest biomass carbon stocks in China over the past 2 decades: Estimation based on integrated inventory and satellite data. Journal of Geophysical Research: Biogeosciences, 110, doi: 10.1029/2005JG000014.

Ren ZZ (2013). Study on the Carbon Sequestration Capacity of the Plantation of Betula Alnoides. PhD dissertation, Kunming University of Science and Technology, Kunming. 72-73. (in Chinese with English abstract) [任治忠 (2013). 西南桦人工林碳汇功能研究. 博士学位论文, 昆明理工 大学, 昆明. 72-73.]

Rice AH, Pyle EH, Saleska SR, Hutyra L, Palace M, Keller M, de Camargo PB, Portilho K, Marques DF, Wofsy SC (2004). Carbon balance and vegetation dynamics in an old-growth Amazonian forest. Ecological Applications,
14, 55-71.

Seely B, Welham C, Kimmins H (2002). Carbon sequestration in a boreal forest ecosystem: Results from the ecosystem simulation model, FORECAST. Forest Ecology and Management, 169, 123-135.

Sleutel S, De Neve S, Hofman G, Boeckx P, Beheydt D, Van Cleemput O, Mestdagh I, Lootens P, Carlier L, van Camp N, Verbeeck H, Vande Walle I, Samson R, Lust N, Lemeur R (2003) Carbon stock changes and carbon sequestration potential of flemish cropland soils. Global Change Biology, 9, 1193-1203.

Sperow M, Eve M, Paustian, K (2003). Potential soil C sequestration on U.S. agricultural soils. Climatic Change, 57, 319-339.

Tang X (2007). Carbon Storage of Forest Vegetation and Spatial Distribution in Sichuan Province. Master degree dissertation, The Graduate School of Sichuan Agricultural University, Yaan. 18-21. (in Chinese with English abstract) [唐霄 (2007). 四川森林植被碳储量估算及其空 间分布特征. 硕士学位论文, 四川农业大学, 雅安. 1821.]

Wang N (2014). Study on Distribution Patterns of Carbon Density and Carbon Stock in the Forest Ecosystem of Shanxi. PhD dissertation, Beijing Forestry University, Beijing. 118-121. (in Chinese with English abstract) [王宁 (2014). 山西森林生态系统碳密度分配格局及碳储量研 究. 博士学位论文, 北京林业大学, 北京. 118-121.]

Wang XC, Qi G, Yu DP, Zhou L, Dai LM (2011). Carbon storage, density, and distribution in forest ecosystems in Jilin Province of Northeast China. Chinese Journal of Applied Ecology, 22, 2013-2020. (in Chinese with English abstract) [王新闯, 齐光, 于大炮, 周莉, 代力民 (2011). 吉林省森林生态系统的碳储量、碳密度及其分布. 应用 生态学报, 22, 2013-2020.]

Wang XK, Feng ZW, Ouyang ZY (2001). Vegetation carbon storage and density of forest ecosystems in China. Chinese Journal of Applied Ecology, 12, 13-16. (in Chinese with English abstract) [王效科, 冯宗炜, 欧阳志云 (2001). 中国森林生态系统的植物碳储量和碳密度研究. 应用 生态学报, 12, 13-16.]

Wang XL, Chang Y, Chen HW, Hu YM, Feng YT, Wu W, Jiao LL (2014a). Biomass allocation characteristics of the main forest ecosystems in the Great Xing'an Mountains, Heilongjiang Province. Chinese Journal of Ecology, 33, 1437-1444. (in Chinese with English abstract) [王晓莉, 常禹, 陈宏伟, 胡远满, 冯玉婷, 吴文, 焦琳琳 (2014a). 黑龙江省大兴安岭主要森林生态系统生物量分配特征. 生态学杂志, 33, 1437-1444.]

Wang XL, Chang Y, Chen HW, Hu YM, Jiao LL, Feng YT, Wu W, Wu HF (2014b). Spatial pattern of forest biomass and its influencing factors in the Great Xing'an Mountains, 
Heilongjiang Province, China. Chinese Journal of Applied Ecology, 25, 974-982. (in Chinese with English abstract) [王晓莉, 常禹, 陈宏伟, 胡远满, 焦琳琳, 冯玉婷, 吴 文, 伍海峰 (2014b). 黑龙江省大兴安岭森林生物量空 间格局及其影响因素. 应用生态学报, 25, 974-982.]

Wang XY, Sun YJ (2008). Review on research and estimation methods of carbon storage in forest ecosystem. World Forestry Research, 21(5), 24-29. (in Chinese with English abstract) [王秀云, 孙玉军 (2008). 森林生态系统碳储 量估测方法及其研究进展. 世界林业研究, 21(5), 24-29.]

Wang Y (2014). Study on Carbon Storage of Forest Vegetation and Its Affecting Factors in the Region South of Miaodao Archipelago. Master degree dissertation, Tianjin University of Technology, Tianjin. 34-36. (in Chinese with English abstract) [王媛 (2014). 庙岛群岛南部岛群森林植被 碳储量及其影响因素研究. 硕士学位论文, 天津理工大 学, 天津. 34-36.]

Wu QB, Wang XK, Duan XN, Deng LB, Lu F, Ouyang ZY, Feng ZW (2008). Carbon sequestration and its potential by forest ecosystems in China. Acta Ecologica Sinica, 28, 517-524. (in Chinese with English abstract) [吴庆标, 王 效科, 段晓男, 邓立斌, 逯非, 欧阳志云, 冯宗炜 (2008). 中国森林生态系统植被固碳现状和潜力. 生态 学报, 28, 517-524.]

Yang HX, Wu B, Zhang JT, Lin DR, Chang SL (2005). Progress of research into carbon fixation and storage of forest ecosystems. Journal of Beijing Normal University (Natural Science), 41, 172-177. (in Chinese with English abstract) [杨洪晓, 吴波, 张金屯, 林德荣, 常顺利 (2005). 森林生态系统的固碳功能和碳储量研究进展. 北京师 范大学学报(自然科学版), 41, 172-177.]

Ye JS, She GH (2010). Forest carbon dynamics in Guangdong Province. Journal of Nanjing Forestry University (Natural
Science Edition), 34(4), 7-12. (in Chinese with English abstract) [叶金盛, 余光辉 (2010). 广东省森林植被碳 储量动态研究. 南京林业大学学报(自然科学版), 34(4), 7-12.]

Zhang WL, Zhang B, Yang CJ, Mei H, Dai QS (2013). Forest litter fall carbon storage estimation of Tibet. Central South Forest Inventory and Planning, 32(4), 12-15. (in Chinese with English abstract) [张万林, 张蓓, 杨传金, 梅浩, 戴 前石 (2013). 西藏自治区森林枯落物碳储量估算. 中南 林业调查规划, 32(4), 12-15.]

Zhang WX, Zhou YD, Huang QL, Zhou YW, Mo LJ (2012). Advances in estimation of vegetation carbon stocks of forest ecosystem in China. Guangdong Forestry Science and Technology, 28(4), 50-55. (in Chinese with English abstract) [张玮辛, 周永东, 黄倩琳, 周永文, 莫罗坚 (2012). 我国森林生态系统植被碳储量估算研究进展. 广东林业科技, 28(4), 50-55.]

Zhang XQ, Xu DY (2003). Potential carbon sequestration in China's forests. Environmental Science \& Policy, 6, 421432.

Zhao M, Zhou GS (2004). Carbon storage of forest vegetation and its relationship with climatic factors. Scientia Geographica Sinica, 24, 50-54. (in Chinese with English abstract) [赵敏, 周广胜 (2004). 中国森林生态系统的 植物碳贮量及其影响因子分析. 地理科学, 24, 50-54.]

Zhen W, Huang M, Zhai YL, Chen K, Gong YZ (2014). Variation of forest vegetation carbon storage and carbon sequestration rate in Liaoning Province, Northeast China. Chinese Journal of Applied Ecology, 25, 1259-1265. (in Chinese with English abstract) [甄伟, 黄玫, 翟印礼, 陈 珂, 龚亚珍 (2014). 辽宁省森林植被碳储量和固碳速率 变化. 应用生态学报, 25, 1259-1265.]

特邀编委: 杜 盛 责任编辑: 李 敏

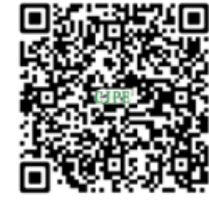

植物生态学报官网

唯一投稿网址

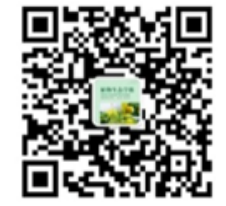

微信订阅号

期刊及学科 相关信息发布

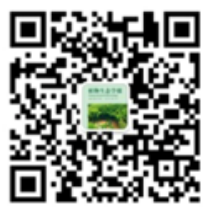

微信服务号

稿件状态查询 全文检索浏览 